\title{
The dietary practices and beliefs of British South Asian people living with inflammatory bowel disease: a multicenter study from the United Kingdom
}

\author{
Benjamin Crooks ${ }^{1,2,3}$, Ravi Misra ${ }^{4}$, Naila Arebi ${ }^{4}$, Klaartje Kok ${ }^{5}$, Matthew J. Brookes ${ }^{6,7}$, John McLaughlin ${ }^{1,2}$, Jimmy K. Limdi ${ }^{1,3}$ \\ ${ }^{I}$ Division of Diabetes, Endocrinology and Gastroenterology, Faculty of Biology, Medicine and Health, The University of Manchester, Manchester; \\ ${ }^{2}$ Department of Gastroenterology, Salford Royal NHS Foundation Trust, Salford; ${ }^{3}$ Section of IBD, Division of Gastroenterology, The Pennine \\ Acute Hospitals NHS Trust, Manchester; ${ }^{4}$ Department of IBD, St Mark's Hospital and Imperial College, London; ${ }^{5}$ Gastroenterology Department, \\ Barts Health NHS Trust, The Royal London Hospital, London; ${ }^{6}$ Gastroenterology Unit, Royal Wolverhampton NHS Trust, Wolverhampton; \\ ${ }^{7}$ Research Institute in Healthcare Science (RIHS), University of Wolverhampton, Wolverhampton, UK
}

Background/Aims: Epidemiological associations have implicated factors associated with Westernization, including the Western diet, in the development of inflammatory bowel disease (IBD). The role of diet in IBD etiopathogenesis, disease control and symptom management remains incompletely understood. Few studies have collected data on the dietary habits of immigrant populations living with IBD. Our aim was to describe the dietary practices and beliefs of British South Asians with IBD. Methods: A 30-item questionnaire was developed and consecutively administered to 255 British South Asians with IBD attending gastroenterology clinics in the United Kingdom. Results: Fifty-one percent of participants believed diet was the initiating factor for their IBD and 63\% felt diet had previously triggered disease relapse. Eighty-nine percent avoided certain dietary items in the belief that this would prevent relapse. The most commonly avoided foods and drinks were spicy and fatty foods, carbonated drinks, milk products, alcohol, coffee, and red meat. A third of patients had tried a whole food exclusion diet, most commonly lactose- or gluten-free, and this was most frequently reported amongst those with clinically active IBD $(P=0.02)$. Almost $60 \%$ of participants avoided eating the same menu as their family, or eating out, at least sometimes, to prevent IBD relapse. Conclusions: British South Asians with IBD demonstrate significant dietary beliefs and food avoidance behaviors with increased frequency compared to those reported in Caucasian IBD populations. Studies in immigrant populations may offer valuable insights into the interaction between diet, Westernization and cultural drift in IBD pathogenesis and symptomatology. (Intest Res 2022;20:53-63)

Key Words: Inflammatory bowel disease; Diet; Crohn disease; Ulcerative colitis; Ethnic groups

\section{INTRODUCTION}

The inflammatory bowel diseases (IBDs), comprising Crohn's disease (CD) and ulcerative colitis (UC), are chronic, relapsing-remitting, inflammatory conditions affecting the gastroin-

Received July 1, 2020. Revised November 16, 2020.

Accepted November 24, 2020.

Correspondence to Jimmy K. Limdi, Section of IBD, Division of Gastroenterology, The Pennine Acute Hospitals NHS Trust, Clinical Research Unit, Fairfield General Hospital, Rochdale Old Road, Bury, Greater Manchester BL9 7TD, UK. Tel: +44-161-7782642, Fax: +44-161-778-2659,

E-mail:jimmy.limdi@nhs.net testinal tract. ${ }^{1}$ The etiopathogenesis of IBD remains incompletely understood but it is generally accepted that these conditions develop as a result of environmental factors acting in a genetically susceptible individual resulting in an aberrant immune response involving the host gut microbiome. ${ }^{2}$ The environmental factors at play, of which many are postulated, remain particularly poorly understood. ${ }^{3}$

Epidemiological studies demonstrate that IBD has become a global phenomenon, with a rising incidence in newly industrialized countries as well as in migrants and their offspring who emigrate from countries of low IBD prevalence into 
countries of high prevalence. ${ }^{4.9}$ As such, environmental factors associated with increasing Westernization such as the "Western diet," high in saturated fats, processed foods, animal protein, refined sugar and low in fiber, fresh fruit and vegetables, have been implicated in IBD development. ${ }^{10}$

Diet is of particular interest to people with IBD, not least because nutrition is essential to life, but also due to the integral role eating plays in socializing with family and friends. This inevitably leads them to gravitate to diet and food in their consultations with clinicians, seeking to improve, control, or even "cure" IBD through diet. ${ }^{11,12}$ Additionally, people with IBD may be at risk of nutritional deficiencies during periods of disease exacerbation (reduced oral intake, malabsorption, nutrient losses through the inflamed gut) and during remission. ${ }^{13-18}$

Whilst diet is of great interest to those living with IBD, there remains a paucity of evidence-based dietary recommendations and advice from healthcare professionals is inevitably limited by a relative dearth of credible scientific data. ${ }^{19,20}$ This fuels frustration due to perceived clinician indifference, leading those living with IBD to seek information from other sources to address their unmet needs. ${ }^{11,21-23}$ The lack of clear dietary advice can result in self-imposed dietary restriction in this group, putting individuals with IBD at further increased risk of nutritional deficiency and impacting on psychosocial wellbeing. ${ }^{11,13,24,25}$

A number of studies have shown a high frequency of dietary avoidance amongst IBD patients as well as varying beliefs regarding the role of diet in their disease. ${ }^{11,26-29}$ A UK-based survey of unselected IBD patients observed that patients described strong beliefs pertaining to the role of dietary intake in IBD initiation and subsequent risk of relapse. ${ }^{11}$ Of interest, British South Asians appeared to hold stronger views with regard to diet and a higher level of consistency around dietary restriction and avoidance of eating out to prevent disease relapse than people of Caucasian heritage. ${ }^{11}$ A major limitation of this observation, however, was that less than $10 \%$ of the study population was of South Asian ethnicity so no strong conclusions could be drawn with respect to ethnic differences. However, a similar study from India demonstrated a high frequency of dietary restriction amongst people with IBD suggesting this is not a geographical effect. ${ }^{30}$

A number of religious and cultural practices impact upon South Asian dietary behavior. Hindus typically do not eat beef for religious reasons and Muslims do not eat pork, also for religious reasons. Vegetarianism is also widely prevalent as part of cultural practice among many people of Indian origin. How- ever, studies indicate that a certain amount of dietary acculturation, that is, assimilation to new cultural practices, may occur following migration to Western countries. ${ }^{31}$ Understanding the dietary habits and perceptions of immigrant populations with IBD may hold vital scientific clues enabling further insights into the complex interaction between diet, effect of migration and "Westernization," and any drift from these traditional cultural practices. Despite this, there are limited data on the dietary habits of the immigrant South Asian population with IBD in the United Kingdom. ${ }^{7,11,32,33}$ The primary aim of our study was to describe the dietary practices and beliefs of British South Asians with IBD. Our secondary aims were to report any significant predictors accounting for the variation observed in responses between people and to describe the information resources utilized by these patients to guide their dietary beliefs and food related behaviors.

\section{METHODS}

\section{Questionnaire Development}

A questionnaire was developed (adapted from our previous study), on the dietary practices and beliefs of British South Asian people living with IBD. ${ }^{11}$ The questionnaire was reviewed by a hospital patient focus group involving British South Asian patients with IBD and then modified based on their suggestions. The finalized questionnaire consisted of 30 questions assessing demographics, disease characteristics, dietary beliefs and practices and the information resources utilized by these patients (Table 1, Supplementary Material 1).

\section{Eligibility Criteria}

Patients were eligible to participate if they were aged 18 or above, had a diagnosis of IBD (confirmed by a combination of endoscopic, radiological, biochemical and histological investigations) and identified themselves as a belonging to an ethnicity originating in South Asia (India, Pakistan, Bangladesh, Nepal, Maldives, Sri Lanka, or Bhutan).

Patients were excluded if they had a history of intestinal resection surgery (those with a previous appendectomy were eligible), if they had a current malignancy (or had been treated for a malignancy within the last 5 years) or if they were currently pregnant.

\section{Disease Phenotype and Activity}

Disease phenotype was described using the Montreal classification. ${ }^{34}$ Disease activity for UC was assessed using a validated 
Table 1. Summary of Questionnaire Contents

Questions for research team:

01. Disease: UC, CD or IBDU?

02. Disease classification (Montreal classification)?

03. Current medications for IBD?

Q4. Latest investigations within the last 3 months (if performed)?

05. Disease activity score: PRO2 for UC, HBI for CD.

Questions for participants:

Q1. How many years ago were you diagnosed with IBD?

Q2. Do you consider that diet is the initiating factor for IBD?

-02-2. What is the source of this information?

03. Have you had a relapse of IBD within the last 1 year?

Q4. Do you consider that a dietary factor has ever triggered a relapse of your IBD?

-04-2. Which food or drink do you think triggered the relapse?

05. Do you consider that diet triggers a relapse of IBD?

Q6. Do you avoid certain foods or drink to try and prevent relapse of IBD?

-06-2. Which foods and drinks do you avoid and what are your sources of information for this (followed by list of dietary items A-M).

07. Do you consider that consuming certain foods, drink or nutritional supplements can prevent a relapse of IBD?

Q8. Do you actually consume certain foods, drink or nutritional supplements to prevent relapse of IBD?

-08-2. Which foods, drink, nutritional supplements?

-08-3. What are your sources of information for this?

Q9. Do you consider that diet should differ between relapse and remission of IBD?

Q10. Do you consider that the diet for preventing relapse of UC differs to that for CD?

Q11. When you search for dietary recommendations, are you able to find specific advice for IBD?

-011-2. What are your information resources?

Q12. Do you avoid the same menu as other members of your family to prevent relapse of IBD?

Q13. Do you avoid eating out for fear of causing a relapse of IBD?

Q14. Have you tried any of these specific diets? (Followed by list of whole food exclusion diets)

Q15. Are you male or female?

016. Participant age?

Q17. Height?

018. Weight?

Q19. In which country were you born?

-019-1. If born in the UK, were your parents also born in the UK?

020. With which South Asian ethnicity do you identify?

021. Do you have any other medical conditions for which you need to avoid certain dietary items?

022. Who do you live with?

Q23. Do you work?

Q24. Highest educational qualification?

025. Do you feel limited in your choices of food or drink because of cost or income?

These are shortened versions of the actual questions. For the full version of the questions and answer options, as they appeared in the participant questionnaire, please refer to the supplementary material.

UC, ulcerative colitis; CD, Crohn's disease; IBD, inflammatory bowel disease; IBDU, IBD unspecified; PRO2, patient reported outcome-2; HBI, Harvey Bradshaw Index.

patient reported outcome 2 (PRO2) and for CD, the Harvey Bradshaw Index (HBI) was used. ${ }^{35,36}$ A PRO2 score of $\leq 1$ (in- cluding a rectal bleeding subscore of zero) and HBI $\leq 4$ was used to define clinical remission. 


\section{Study Design}

This was a cross-sectional, multicenter, descriptive study in the United Kingdom between March 2019 and March 2020. Recruitment centers were The Pennine Acute Hospitals NHS Trust and Salford Royal NHS Foundation Trust in Greater Manchester, The Royal Wolverhampton NHS Trust, London North West Healthcare NHS Trust and Barts Health NHS Trust, London. These were selected on account of a high population density of people with South Asian heritage.

South Asian patients with IBD were consecutively recruited from the gastroenterology clinics at participating centers. Eligible, consenting patients were asked to complete the questionnaire whilst in the clinic. Each patient's clinical disease activity was assessed and details of their medications and recent investigations were recorded by a member of the research team.

\section{Statistical Analysis}

We used IBM SPSS Statistics version 25 (IBM Corp., Armonk, NY, USA) to perform statistical analysis with significance assessed at an $\alpha$ level of 0.05 (two sided). Descriptive statistics were used to define the patient population, disease characteristics and patterns of dietary behaviors and beliefs observed in this population. Seven potential predictors, namely, age, gender, IBD subtype, disease relapse in the previous 12 months, current disease activity, ethnicity and place of birth (UK vs. non-UK) were chosen as possible determinants for the variation observed in responses. Bivariate analysis was performed using Pearson chi-square test for categorical variables and the independent $t$-test for continuous variables. Where applicable, post hoc analysis was performed using the Bonferroni correction for multiple comparisons. Binary logistic regression was used to determine the relationship between significant predictors and the outcome by means of odds ratios (OR) quoted with $95 \%$ confidence intervals (CI).

For the purpose of statistical analysis, only dietary avoidance for the perceived prevention of disease relapse was included when calculating results for patterns of dietary avoidance, rather than avoidance for other reasons such as vegetarianism or religion. The 7 ethnicity choices on the questionnaire were grouped into 4 categories, Indian, Pakistani, Bangladeshi and South Asian (other), due to the small numbers of patients in other South Asian groups.

\section{Ethical Considerations}

Ethical approval for the study was obtained in the United
Kingdom from South West/Central Bristol Research Ethics Committee on March 4, 2019 (REC reference 19/SW/0035) and was adopted onto the National Institute of Health Research (NIHR) portfolio (CPMS ID: 41127). The study was conducted in accordance with the Declaration of Helsinki. Written informed consent was obtained.

\section{RESULTS}

\section{Baseline Characteristics}

Two hundred and fifty-five British South Asians with a diagnosis of IBD participated in the study. Further recruitment was planned but stopped in March 2020 due to the COVID-19 (coronavirus disease 2019) pandemic, when all such studies were suspended or terminated across the UK.

Baseline participant demographics are summarized in Table 2. Mean age was 42 years and $52 \%$ were male. Fifty-four participants (21\%) reported having another medical condition for which they needed to avoid certain food and drink such as diabetes mellitus (13\%). Disease characteristics are summarized in Table 3. One hundred and fifty (59\%) were in clinical remission at the time of recruitment $(\mathrm{PRO} 2 \leq 1$ [with rectal bleeding subscore $=0$ ] for UC and HBI $\leq 4$ for $\mathrm{CD}$ ). One hundred and forty-three (56\%) reported having had a relapse of their IBD in the previous 12 months (relapse was defined as the presence of rectal bleeding with increased bowel habits for UC, and for CD, the presence of abdominal pain with or without increased bowel habits and rectal bleeding).

\section{Dietary Beliefs Regarding Disease Initiation and Control}

Fifty-one percent of participants considered diet to be the initiating factor for their IBD. These beliefs did not vary based on IBD subtype, disease activity, ethnicity, age or any of the other potential predictors analyzed. One hundred and sixty-one (63\%) believed dietary components had previously triggered a relapse of their IBD. Those who reported a disease relapse in the previous 12 months were significantly more likely to hold these beliefs (OR, 1.98; 95\% CI, 1.17-3.36, $P=0.01$ ). The most commonly self-identified dietary triggers for IBD relapse were spicy foods ( $74 \%)$, fatty foods (44\%), red meat (42\%), milk (42\%), alcohol (35\%), and coffee (32\%).

\section{Altered Dietary Practices for the Prevention of Disease Relapse}

Two hundred and twenty-eight respondents (89\%) reported 
Table 2. Participant Baseline Demographics

\begin{tabular}{|c|c|}
\hline Variable & Value $(n=255)$ \\
\hline Age (yr) & $41.8 \pm 14.8(18-85)$ \\
\hline Ratio of M:F & $52: 48$ \\
\hline BMI $\left(\mathrm{kg} / \mathrm{m}^{2}\right)$ & $25.3 \pm 5.4$ \\
\hline \multicolumn{2}{|l|}{ South Asian ethnicity } \\
\hline Indian & $138(54.1)$ \\
\hline Pakistani & $67(26.3)$ \\
\hline Bangladeshi & $42(16.5)$ \\
\hline South Asian-other & $7(2.7)$ \\
\hline Unspecified & $1(0.4)$ \\
\hline \multicolumn{2}{|l|}{ Country of birth } \\
\hline UK & $136(53.3)$ \\
\hline Non-UK & $119(46.7)$ \\
\hline \multicolumn{2}{|l|}{ Living status } \\
\hline With family & $237(93.0)$ \\
\hline Alone & $11(4.3)$ \\
\hline With others & $7(2.7)$ \\
\hline \multicolumn{2}{|l|}{ Highest level of educational qualification } \\
\hline None & $5(2.0)$ \\
\hline High school exams (GCSEs/0-levels in UK) & $53(20.8)$ \\
\hline College/6th form exams (A-levels in UK) & $45(17.6)$ \\
\hline University degree & $108(42.4)$ \\
\hline Other professional qualification (e.g., diploma) & $35(13.7)$ \\
\hline Unspecified & $9(3.5)$ \\
\hline \multicolumn{2}{|l|}{ Employment status } \\
\hline Full-time & $123(48.2)$ \\
\hline Part-time & 45 (17.6) \\
\hline Unemployed & $63(24.7)$ \\
\hline Retired & $22(8.6)$ \\
\hline Unspecified & $2(0.8)$ \\
\hline
\end{tabular}

Values are presented as mean \pm standard deviation (range) or number (\%). $M$, male; $F$, female; BMI, body mass index; GCSE, General Certificate of Secondary Education; 0-levels, ordinary levels; A-levels, advanced levels.

avoiding certain foods or drinks, at least sometimes (27\% "always avoid" and $63 \%$ "sometimes avoid"), holding a belief that this may help prevent a relapse of their IBD. The most commonly avoided dietary products across all participants $(\mathrm{n}=255)$ were spicy foods $(71 \%)$, fatty foods (58\%), carbonated drinks (51\%), milk products (49\%), alcohol (47\%), coffee (47\%), red meat (42\%), sweet foods (33\%), and raw fruit and vegetables (30\%).

There were no significant predictors accounting for the variation seen in responses for general food avoidance. Females
Table 3. Participant IBD Specifics

\begin{tabular}{lc}
\hline Variable & $\begin{array}{c}\text { Value } \\
(\mathrm{n}=255)\end{array}$ \\
\hline Disease duration (yr) & $9.9 \pm 8.7$ \\
IBD subtype and distribution & \\
Ulcerative colitis & $154(60.4)$ \\
E1 (proctitis) & $23(9.0)$ \\
E2 (left sided disease) & $70(27.5)$ \\
E3 (extensive colitis) & $61(23.9)$ \\
Crohn's disease & $93(36.5)$ \\
Ileal & $18(7.1)$ \\
Colonic & $33(12.9)$ \\
Ileocolonic & $39(15.3)$ \\
Unspecified & $3(1.2)$ \\
IBDU & $8(3.1)$ \\
Clinical disease activity (PR02/HBI) & \\
Clinical remission & $150(58.8)$ \\
Active disease & $96(37.6)$ \\
Unavailable & $95(3.5)$ \\
Disease relapse in previous 12 months & $143(56.1)$ \\
Medication & $19(7.5)$ \\
Oral 5-aminosalicylates & $13(5.1)$ \\
Immunomodulators (azathioprine, mercaptopurine, \\
miothotrexate) & \\
Topical 5-aminosalicylates & \\
Oral corticosteroids & \\
\hline & \\
\hline
\end{tabular}

Values are presented as mean \pm standard deviation or number (\%). IBD, inflammatory bowel disease; IBDU, IBD unspecified; PRO2, patient reported outcome-2; HBI, Harvey Bradshaw Index; TNFs, tumor necrosis factors.

were identified as avoiding significantly more dietary products, on average, than males (4.3 vs. 5.2, $P=0.02$ ). Females were significantly more likely to avoid raw fruit and vegetables (OR, 1.78; 95\% CI, 1.04-3.06; $P=0.04$ ) and sweet foods (OR, 2.53; 95\% CI, 1.48-4.33; $P=0.001)$. There were no significant gender differences in food avoidance amongst other food and drink categories (Fig. 1).

Avoidance of fatty foods $(P=0.002)$ and alcohol $(P=0.006)$ were found to vary significantly depending on South Asian ethnicity with Bangladeshi participants most likely to avoid fatty foods $(P=0.004)$ and Indian participants most likely to avoid alcohol $(P<0.001)$ for the purposes of IBD relapse avoidance (Supplementary Fig. 1). Those who were not born in the United Kingdom ( $\mathrm{n}=119)$ were significantly more likely 


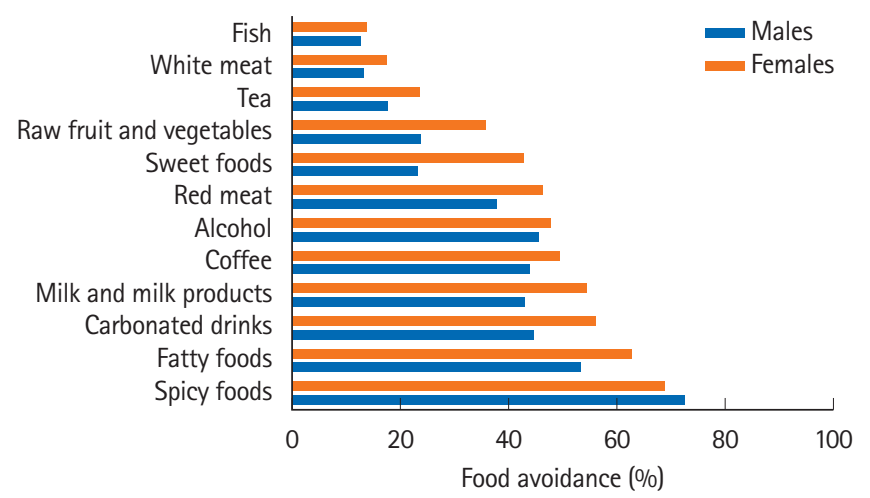

Fig. 1. Gender differences in frequency of food avoidance amongst British South Asians with inflammatory bowel disease.

to avoid white meat (OR, 3.18; 95\% CI, 1.54-6.59; $P=0.002$ ), fish (OR, 2.72; 95\% CI, 1.27-5.86; $P=0.01$ ) and alcohol (OR, 1.66; 95\% CI, 1.01-2.73; $P=0.05$ ) in order to prevent a disease relapse. No significant differences were found between UC and CD patients, or between active and inactive disease, across all dietary subgroups. Participants with a co-existing medical condition $(21 \%)$ requiring them to make dietary modifications were not found to be significantly more likely to avoid dietary components specifically for the purposes of IBD relapse prevention $(P=0.85)$.

Just over half (52\%) believed that consuming certain foods, drinks or nutritional supplements could prevent a relapse of their IBD, however only $39 \%$ reported actually consuming these products. The most commonly consumed items were turmeric products in $10 \%$ and probiotics in $7 \%$. The details of other foods, drinks and nutritional supplements, consumed by patients to prevent disease relapse, are shown in Table 4 .

\section{The Use of Whole Food Exclusion Diets}

A third (31\%) reported having tried a specific whole food exclusion diet. The most common among these was a lactosefree diet (21\%) followed by a gluten-free diet (14\%), low FODMAPs (Fermentable Oligo-, Di-, and Monosaccharides and Polyols) diet (5\%), specific carbohydrate diet (3.2\%), anti-inflammatory diet (3.6\%), and a Paleolithic diet (2\%). Twelve percent reported having tried more than one of these diets. Ethnic differences in the use of whole food exclusion diets are shown in Fig. 2. Those with clinically active IBD were more likely to have tried a whole food exclusion diet (OR, 1.95; 95\% CI, 1.13-3.37; $P=0.02$ ).

\section{Psychosocial Impact}

On analyzing the data regarding avoidance of the same menu
Table 4. Dietary Components Consumed to Prevent Inflammatory Bowel Disease Relapse

\begin{tabular}{lc}
\hline Food/drink/supplement consumed & Frequency (\%) \\
\hline Turmeric products & $26(10.2)$ \\
Probiotics & $17(6.7)$ \\
Oily fish/omega 3 supplements & $10(3.9)$ \\
Fruit and vegetables & $10(3.9)$ \\
Yogurt & $9(3.5)$ \\
Specific types of water & $8(3.1)$ \\
Vitamin D supplements & $6(2.4)$ \\
Multivitamins & $6(2.4)$ \\
Bland/plain/white foods (e.g., rice, bread, potatoes) & $5(2.0)$ \\
Honey & $5(2.0)$ \\
\hline
\end{tabular}

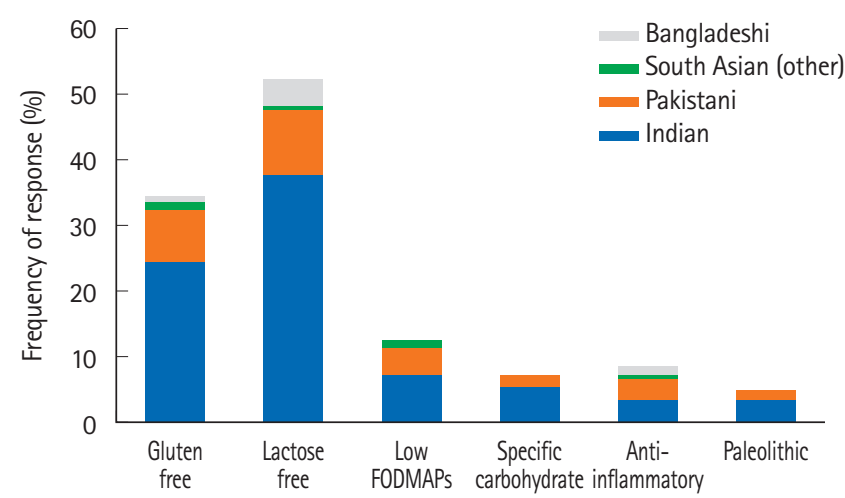

Fig. 2. The use of whole food exclusion diets amongst British South Asians living with inflammatory bowel disease. FODMAPs, Fermentable Oligo-, Di-, and Monosaccharides and Polyols.

as the rest of the family, only responses from those participants who reported living with their family $(\mathrm{n}=237)$ were considered. One hundred and thirty-nine participants (59\%) reported avoiding eating the same meal as their family, at least sometimes, to prevent a relapse of their IBD (16\% "always avoid" and 43\% "sometimes avoid"). A similar number (58\%) avoided eating out for fear of causing a disease relapse $(21 \%$ "always avoid" and 37\% "sometimes avoid"). Just under a fifth (18\%) reported feeling limited in their dietary choices because of cost or income but this did not significantly impact upon likelihood of dietary avoidance or beliefs about the role of diet in IBD initiation.

\section{Information Resources}

Of those who believe that diet is the initiating factor for IBD $(n=129), 95 \%$ based this on their own experience of the disease. The other most commonly used information resources 
Table 5. Information Resources Utilized by British South Asian People Living with IBD

\begin{tabular}{|c|c|c|c|}
\hline Information resource & $\begin{array}{c}\text { Disease } \\
\text { initiation } \\
(\%)\end{array}$ & $\begin{array}{c}\text { Food/drink } \\
\text { avoidance } \\
(\%)\end{array}$ & $\begin{array}{c}\text { Food/drink/ } \\
\text { supplement } \\
\text { use }(\%)\end{array}$ \\
\hline Patient's own experience & 94.6 & 81.7 & 73.0 \\
\hline Healthcare professional & 34.1 & 18.7 & 30.0 \\
\hline Gastroenterologist & 22.5 & 12.2 & 17.0 \\
\hline General practitioner & 3.9 & 2.2 & 3.0 \\
\hline IBD clinical nurse specialist & 14.0 & 4.3 & 4.0 \\
\hline Dietitian & 14.0 & 9.9 & 12.0 \\
\hline Internet & 33.3 & 14.6 & 40.0 \\
\hline $\begin{array}{l}\text { Support organizations } \\
\text { (e.g., CCUK) }\end{array}$ & 23.3 & 8.2 & 11.0 \\
\hline Other & 18.6 & 10.6 & 35.0 \\
\hline Information leaflet/booklet & 3.9 & 1.1 & 2.0 \\
\hline \multicolumn{4}{|c|}{ Information from other patients } \\
\hline UC & 7.0 & 2.6 & 5.0 \\
\hline$C D$ & 7.0 & 2.6 & 7.0 \\
\hline Family & 17.8 & 9.1 & 24.0 \\
\hline Friends & 4.6 & 4.0 & 12.0 \\
\hline Social media & 5.4 & 1.8 & 7.0 \\
\hline Television/radio & 0.8 & 0.8 & 0 \\
\hline Newspapers/magazines & 1.6 & 0.2 & 2.0 \\
\hline
\end{tabular}

IBD, inflammatory bowel disease; CCUK, Crohn's and Colitis UK; UC, ulcerative colitis; CD, Crohn's disease.

guiding these beliefs are the internet (33\%) and advice from healthcare professionals (34\%) (Table 5).

Those who avoid certain foods or drinks to avoid a "relapse" of their IBD ( $n=228)$ were asked to provide details of the information resources used to guide these dietary practices (Table 5). Participants were encouraged to report all sources of information used and, as such, some individuals documented multiple resources. The majority based their decisions regarding dietary avoidance on their own experience with food (82\%). Few reported using advice from healthcare professionals (19\%), most commonly their gastroenterologist (12\%) followed by a dietitian (10\%) and IBD clinical nurse specialist (4\%), as well as information found on the internet (15\%) and advice from their family (9\%).

When considering which foods, drinks or nutritional supplements were beneficial in preventing a disease relapse ( $\mathrm{n}=100)$ individuals relied on their own experience (73\%), information from the internet (40\%) and advice from healthcare professionals (30\%) and family (24\%). Only $11 \%$ of patients reported using internet-based patient support organizations, such as Crohn's and Colitis UK (CCUK), to guide these dietary practices with $35 \%$ using other websites (Table 5).

Half of our participants (51\%) reported being able to find specific advice regarding dietary recommendations for IBD. This information was most frequently sourced via the internet $(65 \%)$ with only $17 \%$ specifically reporting the use of internetbased patient support organizations, such as CCUK, or NHS websites.

\section{DISCUSSION}

Few studies have examined the dietary practices and beliefs of people living with IBD and these have been conducted mainly in Western, predominantly Caucasian, populations with very limited data on immigrant South Asian populations. ${ }^{11,13,26-30,33,37}$ This is the largest study to date reporting on dietary practices and beliefs of South Asian immigrant patients with IBD. The ethnic distribution of our participants (54\% Indian, 36\% Pakistani, and 17\% Bangladeshi) is broadly in keeping with the distribution as recorded in the last UK Census in $2011 .{ }^{38}$ We observed frequent food avoidance and dietary beliefs, with a high level of consistency around perceived triggers, and often higher than noted in our own previously reported Caucasian population in which a similar study design and questionnaire were used. ${ }^{11}$

It is important to note at the outset that this study concerns beliefs and perceptions, based on participants' experiences, and is not asserting any biological or mechanistic underpinning, nor any causality. Many symptoms experienced by people with IBD are transient and functional in nature, but may be misinterpreted as a disease flare and are important to understand. It is anticipated that the interpretation of what constitutes a disease relapse will differ between our participants but the study is designed to focus on alterations in dietary habits based on patient perceived flares rather than proven inflammatory flares.

In our study, $51 \%$ of British South Asians who took part considered diet to be the initiating factor for their IBD. Whilst not directly comparable, these beliefs are broadly similar to those of the predominantly Caucasian IBD population in our prior study where $48 \%$ of 400 participants surveyed held similar beliefs. ${ }^{11}$ Similarly, in the study by Tomar et al. ${ }^{30}$ conducted in India, $44 \%$ of 316 individuals surveyed perceived dietary factors as a risk for the development of IBD.

One might expect perceptions with regard to the role of diet 
in disease initiation to be stronger in an immigrant population who may have shifted towards a more Westernized culture before being diagnosed with their IBD. If this were the case, it may also be expected that beliefs regarding the role of diet in the etiopathogenesis of IBD would be more extreme in those born outside of the UK and who have migrated in before their diagnosis. The finding that there is no difference in these beliefs in our study, depending on where participants were born, indicates that these cultural transitions may have less of an impact on beliefs pertaining to diet than might be anticipated.

A high proportion of our respondents reported avoidance of specific foods and drinks to prevent "relapse" with $89 \%$ of patients reporting dietary avoidance, at least sometimes. This high frequency of avoidance amongst South Asian people with IBD has been noted in other similar studies and, whilst not directly comparable, data indicates that food avoidance with the intention of preventing "relapse" may be more common among South Asian people living with IBD than it is in Caucasian patients. ${ }^{11,26,30}$ The most commonly avoided food and drinks were spicy foods, fatty foods, carbonated drinks, milk products, alcohol, coffee, red meat, sweet foods and raw fruit and vegetables, similar to those reported in other studies. ${ }^{11,13,27,30,37,39}$

The high frequency of avoidance of dairy products, coffee, and fruit and vegetables, all of which can contribute to abdominal symptoms in people without IBD, is suggestive of an overlap with functional gastrointestinal symptoms, such as irritable bowel syndrome. ${ }^{40}$ Spicy foods, alcohol and others can cause symptoms in people with no gastrointestinal disorder at all. ${ }^{13} \mathrm{~A}$ common denominator for symptom improvement with these approaches may be the reduced intake of FODMAPs that can induce symptoms through luminal distension and mechanoreceptor stimulation by virtue of osmotic effects and fermentability. ${ }^{41}$ Thus, many may actually be reporting dietary avoidance in order to prevent unpleasant abdominal symptoms of a functional nature, perceiving this as a disease flare.

We found a high proportion of patients avoiding milk/milk products in our British South Asian IBD cohort compared to a previous study in a predominantly Caucasian population (49\% vs. $15 \%$ in the Limdi et al. study). ${ }^{11}$ This may reflect the high prevalence of lactose intolerance in South Asians and avoidance may improve symptoms related to this rather than true IBD relapse. ${ }^{42,43}$ Complete avoidance of dairy products, however, may raise clinical concern through placing patients at risk of calcium and vitamin D deficiency. ${ }^{11,13,24}$ Avoidance of fruit and vegetables, amongst other dietary products, also carries risk of deficiency of essential vitamins, minerals and trace elements in a group who are already at risk of nutritional deficiency, particularly vitamin $D^{13,44,45}$ The potential for irrational dietary exclusions to impact negatively on health cannot be underestimated and underpins the need for education and research on diet. Dietary counselling has been shown to be effective in managing and preventing nutritional deficiencies in IBD. ${ }^{15}$

A high proportion of British South Asian participants reported avoiding eating the same meal as the rest of the family (59\%) and eating out (58\%), at least sometimes, in a belief this may prevent relapse of their IBD. Concerns such as toilet access may also play a role. This is a higher proportion than noted in the United Kingdom among Caucasians with IBD wherein $25 \%$ reported not sharing meals with the rest of the family and $22 \%$ avoided eating out. ${ }^{11}$ Food intake and associated psychosocial behavior in IBD is also associated with lower quality of life scores. ${ }^{25}$ Similarly, the living with inflammatory bowel disease: the experiences of adults of South Asian origin (LISA) project also reported difficulties with eating the same meal as the rest of the household and avoiding social events due to concern about triggering symptoms. ${ }^{32}$

On review of the information resources utilized by patients to guide their dietary practices and beliefs it is notable that participants' own experiences with food far outweigh information received from a healthcare professional or sourced on the internet. This is perhaps not surprising as clearly an individual is best placed to determine which foods exacerbate their symptoms and might be avoided. Beyond this, partakers reported that advice from a family member is used with almost the same frequency across all fields as advice from a gastroenterologist and more so than information received from a dietitian. This either means that clinicians are not providing adequate dietary advice to IBD patients generally or are failing to engage a specific population of people living with IBD who may already be at increased risk, or both. The LISA project highlighted similar issues, concluding that there was general need for greater information and advice on diet for the wider IBD population but that South Asian patients also needed more culturally specific dietary advice. ${ }^{31}$

Furthermore, whilst the internet is frequently reported as a useful source of information for British South Asian IBD patients, the use of patient support organizations (e.g., CCUK) or NHS websites is reported relatively infrequently. This may reflect under-reporting as some patients who state using the internet as an information resource may not be more specific. The findings do however again echo the findings of the LISA 
report which found that knowledge and understanding of CCUK, as well as engagement with the support group, amongst the British South Asian community was typically very low. ${ }^{32}$ The current study highlights the need to signpost the South Asian IBD community in the direction of credible sources of dietary information in order to avoid the potential risks involved with following non-evidenced based advice. ${ }^{22,23}$ The infrequent reporting of social media as an information resource is of interest in today's society and perhaps is something which could be targeted more. ${ }^{46}$

Our study has a number of limitations. We surveyed an unselected cohort of IBD patients with varying levels of disease activity and it is plausible that individuals with clinically active or sub-clinical but active disease may have dietary beliefs based on current disease activity. There is also the risk of recall bias, an unavoidable issue in self-reported dietary experiences and prior disease "relapses." We also acknowledge that some responses and perceptions are highly likely to be influenced by co-existing functional gut disorders with a very complex cause-effect relationship, but nonetheless influencing dietary beliefs and behaviors. Whilst our definition of UC relapse is fairly robust, involving rectal bleeding and increased stool frequency, we acknowledge that the definition used for self-reported CD relapse is more ambiguous, as are clinical activity scoring systems for CD in general. This may inevitably result in some participants reporting a previous disease relapse, or indeed clinically active disease, when symptoms may be more functional in nature. This is not seen as a limitation as the study was purposefully designed to collect data on participants' dietary beliefs and practices based on patient perceived relapse.

In conclusion, this is the largest study reporting the dietary practices and beliefs of an immigrant population with IBD. British South Asians with IBD demonstrate significant dietary beliefs and food avoidance behaviors with a high level of consistency and more than previously reported in Caucasian people living with IBD. "Westernization" does not appear to have impacted upon beliefs pertaining to the role of diet in disease initiation but may play a role in altered food-related behaviors. Foods that can trigger unpleasant, functional gastrointestinal symptoms appear to be most commonly avoided along with fatty foods, red meat, carbonated drinks and sweet products, which may be associated with perpetuating intestinal inflammation.

As clinicians we need to ensure that we are providing culturally appropriate and competent IBD services and informa- tion resources. The experiences of immigrant populations and minority ethnic groups may hold vital clues which can serve to optimize dietary research in the future allowing us to gain better insight into the complexities surrounding diet, drift from traditional cultural practices, the generation of gastrointestinal symptoms and the propagation of overt inflammation.

\section{ADDITIONAL INFORMATION}

\section{Funding Source}

This work was supported by an investigator-initiated research grant from Takeda (Grant ID ISSR-2018-102453).

\section{Conflict of Interest}

Limdi JK and McLaughlin J have received research support from Takeda. Limdi JK has received consultancy and speaker fees from Abbvie, MSD, Janssen, Takeda and Pfizer. Kok K has received consultancy and speaker fees from Janssen, Takeda, PredictImmune and Amgen. The other authors declare that they have no conflicting interests.

Limdi JK is an editorial board member of the journal but was not involved in the peer reviewer selection, evaluation, or decision process of this article. No other potential conflicts of interest relevant to this article were reported.

\section{Author Contribution}

Conceptualization: McLaughlin J, Limdi JK. Methodology: Crooks B, McLaughlin J, Limdi JK. Formal analysis: Crooks B. Funding acquisition: McLaughlin J, Limdi JK. Project administration: all authors. Visualization: Crooks B, McLaughlin J, Limdi JK. Writing - original draft: Crooks B. Writing - review and editing: Misra R, Arebi N, Kok K, Brookes MJ, McLaughlin J, Limdi JK. Approval of final manuscript: all authors.

\section{Others}

We would like to thank all of the patients and research staff from participating sites in the United Kingdom for their help and support in carrying out this study. We would also like to thank Calvin Heal for his contribution to the statistical analysis of the data for the manuscript.

\section{ORCID}

Crooks B

https://orcid.org/0000-0002-9358-2155

Misra R https://orcid.org/0000-0003-0113-9971

Arebi N https://orcid.org/0000-0001-6976-1690

Kok K 
Brookes MJ

McLaughlin J

Limdi JK

\section{Supplementary Material}

Supplementary materials are available at the Intestinal Research website (https://www.irjournal.org).

\section{REFERENCES}

1. Abraham C, Cho JH. Inflammatory bowel disease. N Engl J Med 2009;361:2066-2078.

2. Zhang YZ, Li YY. Inflammatory bowel disease: pathogenesis. World J Gastroenterol 2014;20:91-99.

3. Ananthakrishnan AN. Environmental risk factors for inflammatory bowel disease. Gastroenterol Hepatol (N Y) 2013;9: 367-374.

4. Ng SC, Shi HY, Hamidi N, et al. Worldwide incidence and prevalence of inflammatory bowel disease in the 21st century: a systematic review of population-based studies. Lancet 2018;390:2769-2778.

5. Misra R, Faiz O, Munkholm P, Burisch J, Arebi N. Epidemiology of inflammatory bowel disease in racial and ethnic migrant groups. World J Gastroenterol 2018;24:424-437.

6. Farrukh A, Mayberry JF. Inflammatory bowel disease and the South Asian diaspora. JGH Open 2019;3:358-360.

7. Probert CS, Jayanthi V, Pinder D, Wicks AC, Mayberry JF. Epidemiological study of ulcerative proctocolitis in Indian migrants and the indigenous population of Leicestershire. Gut 1992;33:687-693.

8. Benchimol EI, Mack DR, Guttmann A, et al. Inflammatory bowel disease in immigrants to Canada and their children: a population-based cohort study. Am J Gastroenterol 2015;110: 553-563.

9. Williams CN. Does the incidence of IBD increase when persons move from a low- to a high-risk area? Inflamm Bowel Dis 2008;14 Suppl 2:S41-S42.

10. Rizzello F, Spisni E, Giovanardi E, et al. Implications of the westernized diet in the onset and progression of IBD. Nutrients 2019;11:1033.

11. Limdi JK, Aggarwal D, McLaughlin JT. Dietary practices and beliefs in patients with inflammatory bowel disease. Inflamm Bowel Dis 2016;22:164-170.

12. Hou JK, Lee D, Lewis J. Diet and inflammatory bowel disease: review of patient-targeted recommendations. Clin Gastroenterol Hepatol 2014;12:1592-1600.
13. Jowett SL, Seal CJ, Phillips E, Gregory W, Barton JR, Welfare MR. Dietary beliefs of people with ulcerative colitis and their effect on relapse and nutrient intake. Clin Nutr 2004;23:161170.

14. Casanova MJ, Chaparro M, Molina B, et al. Prevalence of malnutrition and nutritional characteristics of patients with inflammatory bowel disease. J Crohns Colitis 2017;11:14301439.

15. Richman E, Rhodes JM. Review article: evidence-based dietary advice for patients with inflammatory bowel disease. Aliment Pharmacol Ther 2013;38:1156-1171.

16. Sasson AN, Ananthakrishnan AN, Raman M. Diet in treatment of inflammatory bowel diseases. Clin Gastroenterol Hepatol 2021;19:425-435.

17. Lomer MC, Kodjabashia K, Hutchinson C, Greenfield SM, Thompson RP, Powell JJ. Intake of dietary iron is low in patients with Crohn's disease: a case- control study. Br J Nutr 2004;91:141-148.

18. Hwang C, Ross V, Mahadevan U. Popular exclusionary diets for inflammatory bowel disease: the search for a dietary culprit. Inflamm Bowel Dis 2014;20:732-741.

19. Lamb CA, Kennedy NA, Raine T, et al. British Society of Gastroenterology consensus guidelines on the management of inflammatory bowel disease in adults. Gut 2019;68(Suppl 3):s1-s106.

20. Levine A, Rhodes JM, Lindsay JO, et al. Dietary guidance from the International Organization for the Study of Inflammatory Bowel Diseases. Clin Gastroenterol Hepatol 2020;18:13811392.

21. Holt DQ, Strauss BJ, Moore GT. Patients with inflammatory bowel disease and their treating clinicians have different views regarding diet. J Hum Nutr Diet 2017;30:66-72.

22. Limdi JK, Butcher RO. Information resources and inflammatory bowel disease. Inflamm Bowel Dis 2011;17:E89-E90.

23. Bernstein KI, Promislow S, Carr R, Rawsthorne P, Walker JR, Bernstein CN. Information needs and preferences of recently diagnosed patients with inflammatory bowel disease. Inflamm Bowel Dis 2011;17:590-598.

24. Palant A, Koschack J, Rassmann S, Lucius-Hoene G, Karaus M, Himmel W. "And then you start to loose it because you think about Nutella": the significance of food for people with inflammatory bowel disease - a qualitative study. BMC Gastroenterol 2015;15:93.

25. Czuber-Dochan W, Morgan M, Hughes LD, Lomer MCE, Lindsay JO, Whelan K. Perceptions and psychosocial impact of food, nutrition, eating and drinking in people with inflam- 
matory bowel disease: a qualitative investigation of food-related quality of life. J Hum Nutr Diet 2020;33:115-127.

26. Zallot C, Quilliot D, Chevaux JB, et al. Dietary beliefs and behavior among inflammatory bowel disease patients. Inflamm Bowel Dis 2013;19:66-72.

27. Cohen AB, Lee D, Long MD, et al. Dietary patterns and selfreported associations of diet with symptoms of inflammatory bowel disease. Dig Dis Sci 2013;58:1322-1328.

28. Principi M, Losurdo G, Iannone A, et al. Differences in dietary habits between patients with inflammatory bowel disease in clinical remission and a healthy population. Ann Gastroenterol 2018;31:469-473.

29. Crooks B, McLaughlin J, Matsuoka K, Kobayashi T, Yamazaki $\mathrm{H}$, Limdi JK. The dietary practices and beliefs of people living with inactive ulcerative colitis. Eur J Gastroenterol Hepatol 2021;33:372-379.

30. Tomar SK, Kedia S, Upadhyay AD, et al. Impact of dietary beliefs and practices on patients with inflammatory bowel disease: an observational study from India. JGH Open 2017;1:1521.

31. Holmboe-Ottesen G, Wandel M. Changes in dietary habits after migration and consequences for health: a focus on South Asians in Europe. Food Nutr Res 2012;56:18891.

32. Mukherjee S, Beresford B, Atkin K, Sebastian S. The need for culturally competent care within gastroenterology services: evidence from research with adults of South Asian origin living with inflammatory bowel disease. J Crohns Colitis 2021; 15:14-23.

33. Probert CS, Bhakta P, Bhamra B, Jayanthi V, Mayberry JF. Diet of South Asians with inflammatory bowel disease. Arq Gastroenterol 1996;33:132-135.

34. Silverberg MS, Satsangi J, Ahmad T, et al. Toward an integrated clinical, molecular and serological classification of inflammatory bowel disease: report of a Working Party of the 2005 Montreal World Congress of Gastroenterology. Can J Gastroenterol 2005;19 Suppl A:5A-36A.

35. Jairath V, Khanna R, Zou GY, et al. Development of interim pa- tient-reported outcome measures for the assessment of ulcerative colitis disease activity in clinical trials. Aliment Pharmacol Ther 2015;42:1200-1210.

36. Harvey RF, Bradshaw JM. A simple index of Crohn's-disease activity. Lancet 1980;1:514.

37. Vagianos K, Clara I, Carr R, et al. What are adults with inflammatory bowel disease (IBD) eating? A closer look at the dietary habits of a population-based Canadian IBD cohort. JPEN J Parenter Enteral Nutr 2016;40:405-411.

38. Office for National Statistics. 2011 Census aggregate data. UK data service [Internet]. c2011 [cited 2020 Nov 30]. https:// www.ons.gov.uk/census/2011census/2011censusdata.

39. Kinsey L, Burden S. A survey of people with inflammatory bowel disease to investigate their views of food and nutritional issues. Eur J Clin Nutr 2016;70:852-854.

40. Hayes P, Corish C, O'Mahony E, Quigley EM. A dietary survey of patients with irritable bowel syndrome. J Hum Nutr Diet. 2014 Apr;27 Suppl 2:36-47.

41. Cox SR, Prince AC, Myers CE, et al. Fermentable carbohydrates [FODMAPs] exacerbate functional gastrointestinal symptoms in patients with inflammatory bowel disease: a randomised, double-blind, placebo-controlled, cross-over, rechallenge trial. J Crohns Colitis 2017;11:1420-1429.

42. Malik TF, Panuganti KK. Lactose intolerance. Treasure Island: StatPearls Publishing, 2020.

43. Szilagyi A, Galiatsatos P, Xue X. Systematic review and metaanalysis of lactose digestion, its impact on intolerance and nutritional effects of dairy food restriction in inflammatory bowel diseases. Nutr J 2016;15:67.

44. Ananthakrishnan AN. Vitamin D and inflammatory bowel disease. Gastroenterol Hepatol (N Y) 2016;12:513-515.

45. Lim HS, Kim SK, Hong SJ. Food elimination diet and nutritional deficiency in patients with inflammatory bowel disease. Clin Nutr Res 2018;7:48-55.

46. Reich J, Guo L, Groshek J, et al. Social media use and preferences in patients with inflammatory bowel disease. Inflamm Bowel Dis 2019;25:587-591. 
See "The dietary practices and beliefs of British South Asian people living with inflammatory bowel disease: a multicenter study from the United Kingdom" on page 53-63.

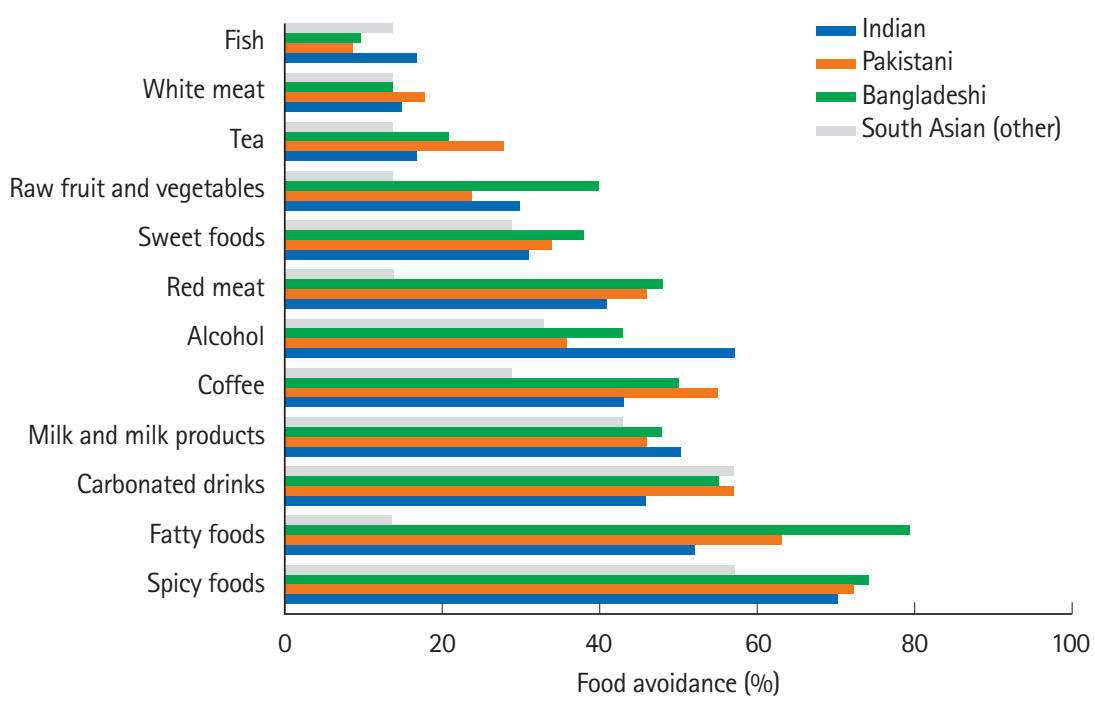

Supplementary Fig. 1. Ethnic differences in frequency of food avoidance amongst British South Asians with inflammatory bowel disease. 
Supplementary Material 1. A questionnaire study on dietary practices and beliefs in South Asian patients with inflammatory bowel disease

\section{A Questionnaire Study on Dietary Practices and Beliefs in South Asian patients with Inflammatory Bowel Disease}

(Version 1.0, 24 $4^{\text {th }}$ January 2019)

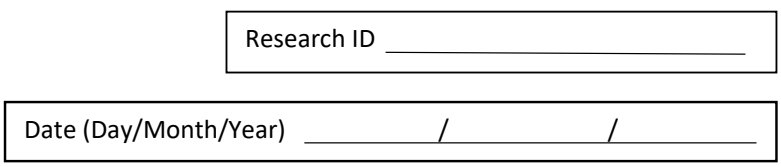

\section{Questions for the research team to complete}

Please circle the appropriate number.

Example:

\begin{tabular}{|c|c|}
\hline (1.) Yes & 2. No \\
\hline
\end{tabular}

Q1. Does the patient have Ulcerative colitis (UC), Crohn's Disease (CD) or IBD unspecified?

\begin{tabular}{l|l|l} 
1. UC & 2. CD & 3. IBDU \\
\hline
\end{tabular}

Q2. What is the extent of this patient's disease?

Please complete table 2.1 for UC or 2.2 for CD

\begin{tabular}{|c|l|}
\hline $\begin{array}{l}\text { 2.1 Ulcerative Colitis } \\
\text { (please circle) }\end{array}$ & \\
\hline E1 & Ulcerative proctitis: limited to rectum \\
\hline E2 & Left-sided UC: distal to splenic flexure \\
\hline E3 & $\begin{array}{l}\text { Extensive UC: extends proximal to splenic } \\
\text { flexure }\end{array}$ \\
\hline
\end{tabular}

\begin{tabular}{|c|c|}
\hline 2.2 Crohn's Disease & \\
\hline Age (please circle) & \\
\hline A1 & 16 years or younger \\
\hline A2 & $17-40$ years \\
\hline A3 & $>40$ years \\
\hline Location (please circle) & Terminal ileum \\
\hline L1 & Colon \\
\hline L2 & Ileocolonic \\
\hline L3 & Upper GI \\
\hline L4 & \\
\hline Behaviour (please circle) & Non-stricturing/Non-penetrating \\
\hline B1 & Stricturing \\
\hline B2 & Penetrating \\
\hline B3 & \\
\hline
\end{tabular}


Q3. Which medications is this patient on for IBD?

\begin{tabular}{|l|c|c|}
\hline 1. Oral 5-aminosalicylic acids (Mesalazine or Sulfasalazine) & 1. Yes & 2. No \\
\hline 2. Immunomodulators (Azathioprine, Mercaptopurine, or Methotrexate) & 1. Yes & 2. No \\
\hline 3. Biologics (Infliximab, Adalimumab, Golimumab, Vedolizumab, etc) & 1. Yes & 2. No \\
\hline 4. Topical 5-aminosalicylic acids (Enema or suppository) & 1. Yes & 2. No \\
\hline 5. Others (please specify & 1. Yes & 2. No \\
\hline
\end{tabular}

Q4. Latest investigation results within last 3 months (if performed).

\begin{tabular}{|c|c|c|}
\hline & Result & Date performed \\
\hline CRP & & \\
\hline Faecal Calprotectin & & \\
\hline $\begin{array}{c}\text { Flexible } \\
\text { Sigmoidoscopy/Colonoscopy }\end{array}$ & & \\
\hline $\begin{array}{c}\text { Abdominal Radiology } \\
\text { (USS/CT/MRI) }\end{array}$ & & \\
\hline
\end{tabular}

Q5. Disease Activity Score (Please complete 5.1 for UC and 5.2 for CD)

\begin{tabular}{|c|l|}
\hline \multicolumn{2}{|l|}{ 5.1 Ulcerative Colitis (please circle) } \\
\hline A. Stool Frequency (Total number of stools/day) \\
\hline 0 & Normal number of stools for this patient \\
\hline 1 & $1-2$ stools/day more than normal for this patient \\
\hline 2 & $3-4$ stools/day more than normal for this patient \\
\hline 3 & $\geq 5$ stools/day more than normal for this patient \\
\hline B. Rectal Bleeding \\
\hline 0 & No blood seen \\
\hline 1 & Streaks of blood seen with $<50 \%$ of stools \\
\hline 2 & Obvious blood seen with $\geq 50 \%$ of stools \\
\hline 3 & Blood alone passed \\
\hline
\end{tabular}




\begin{tabular}{|c|c|}
\hline 5.2 Crohn's Disease (Please circle score) & \\
\hline \multirow[t]{5}{*}{ General well-being } & Very well $=0$ \\
\hline & Slightly below par $=1$ \\
\hline & Poor $=2$ \\
\hline & Very poor $=3$ \\
\hline & Terrible $=4$ \\
\hline \multirow[t]{4}{*}{ Abdominal Pain } & None $=0$ \\
\hline & Mild $=1$ \\
\hline & Moderate $=2$ \\
\hline & Severe $=3$ \\
\hline \multicolumn{2}{|l|}{ Number of liquid stools per day } \\
\hline \multirow[t]{9}{*}{ Complications } & None $=0$ \\
\hline & Arthralgia $=1$ \\
\hline & Uveitis $=1$ \\
\hline & Erythema nodosum $=1$ \\
\hline & Aphthous ulcers $=1$ \\
\hline & Pyoderma gangrenosum $=1$ \\
\hline & Anal fissure $=1$ \\
\hline & New fistula $=1$ \\
\hline & Abscess $=1$ \\
\hline Total Score & \\
\hline
\end{tabular}




\section{Questions for patients}

Please circle the appropriate number.

(Example)

\begin{tabular}{|l|l|}
\hline (1.) Yes & 2. No \\
\hline
\end{tabular}

Q1. How many years ago were you diagnosed with Inflammatory Bowel Disease (IBD)? years

Q2. Do you consider that diet is the initiating factor for Inflammatory Bowel Disease?

\begin{tabular}{|l|l|} 
1. Yes & 2. No \\
\hline
\end{tabular}

If your answer is No, please go to Q3

Q2-2. If $\underline{\text { Yes, }}$ what is the source of this information? (Choose as many as apply)

\begin{tabular}{|l|l|}
\hline 1. & Your own experience \\
\hline 2. & Gastroenterologist / IBD specialist \\
\hline 3. & General practitioner \\
\hline 4. & IBD nurse specialist / other nurse \\
\hline 5. & Dietitian \\
\hline 6. & Internet (patient support organization such as Crohn's and Colitis UK) \\
\hline 7. & Internet (Other websites) \\
\hline 8. & Information leaflet / book for IBD \\
\hline 9. & Other patients with Ulcerative Colitis \\
\hline 10. & Other patients with Crohn's disease \\
\hline 11. & Family \\
\hline 12. & Friends \\
\hline 13. & Social media \\
\hline 14. & Television or Radio \\
\hline 15. & Newspapers and magazines \\
\hline 16. & Other, please specify $\ldots \ldots \ldots \ldots \ldots \ldots \ldots \ldots \ldots \ldots \ldots \ldots \ldots \ldots \ldots \ldots \ldots \ldots \ldots \ldots \ldots \ldots \ldots \ldots \ldots \ldots \ldots \ldots \ldots \ldots \ldots \ldots \ldots \ldots \ldots \ldots$ \\
\hline
\end{tabular}


Q3. Have you had a relapse of Inflammatory Bowel Disease within the last 1 year? (In ulcerative colitis relapse is the presence of rectal bleeding with increased bowel habits. In Crohn's disease relapse is the presence of abdominal pain with or without increased bowel habits and rectal bleeding)

\begin{tabular}{|c|c|}
\hline 1. Yes & 2. No \\
\hline
\end{tabular}

Q4. Do you consider that a dietary factor has ever triggered a relapse of your Inflammatory Bowel Disease?

\begin{tabular}{|c|c|}
\hline 1. Yes & 2 . No \\
\hline
\end{tabular}

If your answer is No, please go to Q5

Q4-2. If Yes, which food or drink do you think triggered the relapse? (Choose as many as apply)

\begin{tabular}{|l|l|}
\hline 1. & Fatty Foods \\
\hline 2. & White meat (e.g. chicken) \\
\hline 3. & Red meat (e.g. beef, lamb, pork) \\
\hline 4. & Milk or milk products \\
\hline 5. & Raw vegetables or raw fruit \\
\hline 6. & Fish \\
\hline 7. & Spicy Foods \\
\hline 8. & Sweet foods \\
\hline 9. & Alcohol \\
\hline 10. & Carbonated drinks \\
\hline 11. & Coffee \\
\hline 12. & Tea \\
\hline 13. & Other, please specify $\ldots \ldots \ldots \ldots \ldots \ldots \ldots \ldots \ldots \ldots \ldots \ldots \ldots \ldots \ldots \ldots \ldots \ldots \ldots \ldots \ldots \ldots \ldots \ldots \ldots \ldots \ldots \ldots \ldots \ldots \ldots \ldots \ldots \ldots \ldots \ldots \ldots$ \\
\hline
\end{tabular}

Q5. Do you consider that diet triggers a relapse of Inflammatory Bowel Disease?

\begin{tabular}{|c|c|}
\hline 1. Yes & 2. No \\
\hline
\end{tabular}

Q6. Do you avoid certain foods or drink to try and prevent relapse of Inflammatory Bowel Disease?
1. I always avoid
2. I sometimes avoid
3. I do not avoid

If you answered "I do not avoid" please go to Q7

Q6-2. If you always or sometimes avoid certain foods or drink to prevent a relapse of Inflammatory Bowel Disease, which food or drink do you avoid (see options on next page)? 


\section{A. Fatty Foods}

\begin{tabular}{|c|r|c|}
\hline 1. I always avoid & 2. I sometimes avoid & 3. I do not avoid \\
\hline If you answered "I do not avoid" please go to B
\end{tabular}

A-2. If you always or sometimes avoid fatty foods to prevent a relapse, what is the source of this information? (Choose as many as apply)

\begin{tabular}{|l|l|}
\hline 1. & Your own experience \\
\hline 2. & Gastroenterologist / IBD specialist \\
\hline 3. & General practitioner \\
\hline 4. & IBD nurse specialist / other nurse \\
\hline 5. & Dietitian \\
\hline 6. & Internet (patient support organization such as Crohn's and Colitis UK) \\
\hline 7. & Internet (Other websites) \\
\hline 8. & Information leaflet / book for IBD \\
\hline 9. & Other patients with Ulcerative Colitis \\
\hline 10. & Other patients with Crohn's disease \\
\hline 11. & Family \\
\hline 12. & Friends \\
\hline 13. & Social media \\
\hline 14. & Television or Radio \\
\hline 15. & Newspapers and magazines \\
\hline 16. & Other, please specify $\ldots \ldots \ldots \ldots \ldots \ldots \ldots \ldots \ldots \ldots \ldots \ldots \ldots \ldots \ldots \ldots \ldots \ldots \ldots \ldots \ldots \ldots \ldots \ldots \ldots \ldots \ldots \ldots \ldots \ldots \ldots \ldots \ldots \ldots \ldots \ldots$ \\
\hline
\end{tabular}

\section{B. White meat (e.g. chicken)}

\begin{tabular}{|c|r|c|}
\hline 1. I always avoid & 2. I sometimes avoid & 3. I do not avoid \\
\hline If you answered "I do not avoid" please go to $\mathbf{C}$
\end{tabular}

B-2. If you always or sometimes avoid white meat to prevent a relapse, what is the source of this information? (Choose as many as apply)

\begin{tabular}{|l|l|}
\hline 1. & Your own experience \\
\hline 2. & Gastroenterologist / IBD specialist \\
\hline 3. & General practitioner \\
\hline 4. & IBD nurse specialist / other nurse \\
\hline 5. & Dietitian \\
\hline 6. & Internet (patient support organization such as Crohn's and Colitis UK) \\
\hline 7. & Internet (Other websites) \\
\hline 8. & Information leaflet / book for IBD \\
\hline 9. & Other patients with Ulcerative Colitis \\
\hline 10. & Other patients with Crohn's disease \\
\hline 11. & Family \\
\hline 12. & Friends \\
\hline 13. & Social media \\
\hline 14. & Television or Radio \\
\hline 15. & Newspapers and magazines \\
\hline 16. & Other, please specify $\ldots \ldots \ldots \ldots \ldots \ldots \ldots \ldots \ldots \ldots \ldots \ldots \ldots \ldots \ldots \ldots \ldots \ldots \ldots \ldots \ldots \ldots \ldots \ldots \ldots \ldots \ldots \ldots \ldots \ldots \ldots \ldots \ldots \ldots \ldots \ldots \ldots \ldots \ldots \ldots$ \\
\hline
\end{tabular}


C. Red Meat (e.g. beef, lamb, pork)

\begin{tabular}{|c|c|c|}
\hline 1. I always avoid & 2. I sometimes avoid & 3. I do not avoid \\
\hline If you answered "I do not avoid" please go to D
\end{tabular}

C-2. If you always or sometimes avoid red meat to prevent a relapse, what is the source of this information? (Choose as many as apply)

\begin{tabular}{|l|l|}
\hline 1. & Your own experience \\
\hline 2. & Gastroenterologist / IBD specialist \\
\hline 3. & General practitioner \\
\hline 4. & IBD nurse specialist / other nurse \\
\hline 5. & Dietitian \\
\hline 6. & Internet (patient support organization such as Crohn's and Colitis UK) \\
\hline 7. & Internet (Other websites) \\
\hline 8. & Information leaflet / book for IBD \\
\hline 9. & Other patients with Ulcerative Colitis \\
\hline 10. & Other patients with Crohn's disease \\
\hline 11. & Family \\
\hline 12. & Friends \\
\hline 13. & Social media \\
\hline 14. & Television or Radio \\
\hline 15. & Newspapers and magazines \\
\hline 16. & Other, please specify $\ldots \ldots \ldots \ldots \ldots \ldots \ldots \ldots \ldots \ldots \ldots \ldots \ldots \ldots \ldots \ldots \ldots \ldots \ldots \ldots \ldots \ldots \ldots \ldots \ldots \ldots \ldots \ldots \ldots \ldots \ldots \ldots \ldots \ldots \ldots \ldots$ \\
\hline
\end{tabular}

D. Milk or milk products

\begin{tabular}{|c|c|c|}
\hline 1. I always avoid & 2. I sometimes avoid & 4. I do not avoid \\
\hline
\end{tabular}

D-2. If you always or sometimes avoid milk or milk products to prevent a relapse, what is the source of this information? (Choose as many as apply)

\begin{tabular}{|l|l|}
\hline 1. & Your own experience \\
\hline 2. & Gastroenterologist / IBD specialist \\
\hline 3. & General practitioner \\
\hline 4. & IBD nurse specialist / other nurse \\
\hline 5. & Dietitian \\
\hline 6. & Internet (patient support organization such as Crohn's and Colitis UK) \\
\hline 7. & Internet (Other websites) \\
\hline 8. & Information leaflet / book for IBD \\
\hline 9. & Other patients with Ulcerative Colitis \\
\hline 10. & Other patients with Crohn's disease \\
\hline 11. & Family \\
\hline 12. & Friends \\
\hline 13. & Social media \\
\hline 14. & Television or Radio \\
\hline 15. & Newspapers and magazines \\
\hline 16. & Other, please specify $\ldots \ldots \ldots \ldots \ldots \ldots \ldots \ldots \ldots \ldots \ldots \ldots \ldots \ldots \ldots \ldots \ldots \ldots \ldots \ldots \ldots \ldots \ldots \ldots \ldots \ldots \ldots \ldots \ldots \ldots \ldots \ldots \ldots \ldots \ldots \ldots \ldots$ \\
\hline
\end{tabular}


E. Raw vegetables or raw fruit

\begin{tabular}{|c|c|c|}
\hline 1. I always avoid & 2. I sometimes avoid & 3. I do not avoid \\
\hline If you answered "I do not avoid" please go to $\mathbf{F}$
\end{tabular}

E-2. If you always or sometimes avoid raw vegetables or raw fruit to prevent a relapse, what is the source of this information? (Choose as many as apply)

\begin{tabular}{|l|l|}
\hline 1. & Your own experience \\
\hline 2. & Gastroenterologist / IBD specialist \\
\hline 3. & General practitioner \\
\hline 4. & IBD nurse specialist / other nurse \\
\hline 5. & Dietitian \\
\hline 6. & Internet (patient support organization such as Crohn's and Colitis UK) \\
\hline 7. & Internet (Other websites) \\
\hline 8. & Information leaflet / book for IBD \\
\hline 9. & Other patients with Ulcerative Colitis \\
\hline 10. & Other patients with Crohn's disease \\
\hline 11. & Family \\
\hline 12. & Friends \\
\hline 13. & Social media \\
\hline 14. & Television or Radio \\
\hline 15. & Newspapers and magazines \\
\hline 16. & Other, please specify $\ldots \ldots \ldots \ldots \ldots \ldots \ldots \ldots \ldots \ldots \ldots \ldots \ldots \ldots \ldots \ldots \ldots \ldots \ldots \ldots \ldots \ldots \ldots \ldots \ldots \ldots \ldots \ldots \ldots \ldots \ldots \ldots \ldots \ldots \ldots \ldots \ldots \ldots$ \\
\hline
\end{tabular}

\section{F. Fish}

\begin{tabular}{|c|c|c|}
\hline 1. I always avoid & 2. I sometimes avoid & 3. I do not avoid \\
\hline
\end{tabular}

F-2. If you always or sometimes avoid fish to prevent a relapse, what is the source of this information? (Choose as many as apply)

\begin{tabular}{|l|l|}
\hline 1. & Your own experience \\
\hline 2. & Gastroenterologist / IBD specialist \\
\hline 3. & General practitioner \\
\hline 4. & IBD nurse specialist / other nurse \\
\hline 5. & Dietitian \\
\hline 6. & Internet (patient support organization such as Crohn's and Colitis UK) \\
\hline 7. & Internet (Other websites) \\
\hline 8. & Information leaflet / book for IBD \\
\hline 9. & Other patients with Ulcerative Colitis \\
\hline 10. & Other patients with Crohn's disease \\
\hline 11. & Family \\
\hline 12. & Friends \\
\hline 13. & Social media \\
\hline 14. & Television or Radio \\
\hline 15. & Newspapers and magazines \\
\hline 16. & Other, please specify $\ldots \ldots \ldots \ldots \ldots \ldots \ldots \ldots \ldots \ldots \ldots \ldots \ldots \ldots \ldots \ldots \ldots \ldots \ldots \ldots \ldots \ldots \ldots \ldots \ldots \ldots \ldots \ldots \ldots \ldots \ldots \ldots \ldots \ldots \ldots \ldots \ldots \ldots \ldots \ldots$ \\
\hline
\end{tabular}




\section{G. Spicy Foods}

\begin{tabular}{|c|c|c|}
\hline 1. I always avoid & 2. I sometimes avoid & 3. I do not avoid \\
\hline If you answered "I do not avoid" please go to $\mathbf{H}$ &
\end{tabular}

G-2. If you always or sometimes avoid spicy foods to prevent a relapse, what is the source of this information? (Choose as many as apply)

\begin{tabular}{|l|l|}
\hline 1. & Your own experience \\
\hline 2. & Gastroenterologist / IBD specialist \\
\hline 3. & General practitioner \\
\hline 4. & IBD nurse specialist / other nurse \\
\hline 5. & Dietitian \\
\hline 6. & Internet (patient support organization such as Crohn's and Colitis UK) \\
\hline 7. & Internet (Other websites) \\
\hline 8. & Information leaflet / book for IBD \\
\hline 9. & Other patients with Ulcerative Colitis \\
\hline 10. & Other patients with Crohn's disease \\
\hline 11. & Family \\
\hline 12. & Friends \\
\hline 13. & Social media \\
\hline 14. & Television or Radio \\
\hline 15. & Newspapers and magazines \\
\hline 16. & Other, please specify $\ldots \ldots \ldots \ldots \ldots \ldots \ldots \ldots \ldots \ldots \ldots \ldots \ldots \ldots \ldots \ldots \ldots \ldots \ldots \ldots \ldots \ldots \ldots \ldots \ldots \ldots \ldots \ldots \ldots \ldots \ldots \ldots \ldots \ldots \ldots$ \\
\hline
\end{tabular}

\section{H. Sweet Foods}

\begin{tabular}{|c|c|c|}
\hline 1. I always avoid & 2. I sometimes avoid & 3 . I do not avoid \\
\hline
\end{tabular}

H-2. If you always or sometimes avoid sweet foods to prevent a relapse, what is the source of this information? (Choose as many as apply)

\begin{tabular}{|l|l|}
\hline 1. & Your own experience \\
\hline 2. & Gastroenterologist / IBD specialist \\
\hline 3. & General practitioner \\
\hline 4. & IBD nurse specialist / other nurse \\
\hline 5. & Dietitian \\
\hline 6. & Internet (patient support organization such as Crohn's and Colitis UK) \\
\hline 7. & Internet (Other websites) \\
\hline 8. & Information leaflet / book for IBD \\
\hline 9. & Other patients with Ulcerative Colitis \\
\hline 10. & Other patients with Crohn's disease \\
\hline 11. & Family \\
\hline 12. & Friends \\
\hline 13. & Social media \\
\hline 14. & Television or Radio \\
\hline 15. & Newspapers and magazines \\
\hline 16. & Other, please specify $\ldots \ldots \ldots \ldots \ldots \ldots \ldots \ldots \ldots \ldots \ldots \ldots \ldots \ldots \ldots \ldots \ldots \ldots \ldots \ldots \ldots \ldots \ldots \ldots \ldots \ldots \ldots \ldots \ldots \ldots \ldots \ldots \ldots \ldots \ldots \ldots \ldots \ldots \ldots$ \\
\hline
\end{tabular}


I. Alcohol

\begin{tabular}{|c|c|c|}
\hline 1. I always avoid & 2. I sometimes avoid & 3. I do not avoid \\
\hline
\end{tabular}

I-2. If you always or sometimes avoid alcohol to prevent a relapse, what is the source of this information? (Choose as many as apply)

\begin{tabular}{|l|l|}
\hline 1. & Your own experience \\
\hline 2. & Gastroenterologist / IBD specialist \\
\hline 3. & General practitioner \\
\hline 4. & IBD nurse specialist / other nurse \\
\hline 5. & Dietitian \\
\hline 6. & Internet (patient support organization such as Crohn's and Colitis UK) \\
\hline 7. & Internet (Other websites) \\
\hline 8. & Information leaflet / book for IBD \\
\hline 9. & Other patients with Ulcerative Colitis \\
\hline 10. & Other patients with Crohn's disease \\
\hline 11. & Family \\
\hline 12. & Friends \\
\hline 13. & Social media \\
\hline 14. & Television or Radio \\
\hline 15. & Newspapers and magazines \\
\hline 16. & Other, please specify $\ldots \ldots \ldots \ldots \ldots \ldots \ldots \ldots \ldots \ldots \ldots \ldots \ldots \ldots \ldots \ldots \ldots \ldots \ldots \ldots \ldots \ldots \ldots \ldots \ldots \ldots \ldots \ldots \ldots \ldots \ldots \ldots \ldots \ldots \ldots \ldots \ldots \ldots \ldots$ \\
\hline
\end{tabular}

\section{J. Carbonated Drinks}

\begin{tabular}{|c|c|c|}
\hline 1. I always avoid & 2 . I sometimes avoid & 3. I do not avoid \\
\hline
\end{tabular}

J-2. If you always or sometimes avoid carbonated drinks to prevent a relapse, what is the source of this information? (Choose as many as apply)

\begin{tabular}{|c|c|}
\hline 1. & Your own experience \\
\hline 2. & Gastroenterologist / IBD specialist \\
\hline 3. & General practitioner \\
\hline 4. & IBD nurse specialist / other nurse \\
\hline 5. & Dietitian \\
\hline 6. & Internet (patient support organization such as Crohn's and Colitis UK) \\
\hline 7. & Internet (Other websites) \\
\hline 8. & Information leaflet / book for IBD \\
\hline 9. & Other patients with Ulcerative Colitis \\
\hline 10. & Other patients with Crohn's disease \\
\hline 11. & Family \\
\hline 12. & Friends \\
\hline 13. & Social media \\
\hline 14. & Television or Radio \\
\hline 15. & Newspapers and magazines \\
\hline 16. & 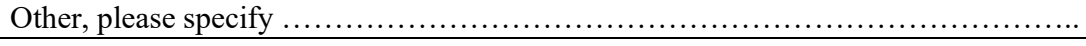 \\
\hline
\end{tabular}




\section{K. Coffee}

\begin{tabular}{|c|r|c|}
\hline 1. I always avoid & 2. I sometimes avoid & 3. I do not avoid \\
\hline
\end{tabular}

K-2. If you always or sometimes avoid coffee to prevent a relapse, what is the source of this information? (Choose as many as apply)

\begin{tabular}{|l|l|}
\hline 1. & Your own experience \\
\hline 2. & Gastroenterologist / IBD specialist \\
\hline 3. & General practitioner \\
\hline 4. & IBD nurse specialist / other nurse \\
\hline 5. & Dietitian \\
\hline 6. & Internet (patient support organization such as Crohn's and Colitis UK) \\
\hline 7. & Internet (Other websites) \\
\hline 8. & Information leaflet / book for IBD \\
\hline 9. & Other patients with Ulcerative Colitis \\
\hline 10. & Other patients with Crohn's disease \\
\hline 11. & Family \\
\hline 12. & Friends \\
\hline 13. & Social media \\
\hline 14. & Television or Radio \\
\hline 15. & Newspapers and magazines \\
\hline 16. & Other, please specify $\ldots \ldots \ldots \ldots \ldots \ldots \ldots \ldots \ldots \ldots \ldots \ldots \ldots \ldots \ldots \ldots \ldots \ldots \ldots \ldots \ldots \ldots \ldots \ldots \ldots \ldots \ldots \ldots \ldots \ldots \ldots \ldots \ldots \ldots \ldots \ldots \ldots$ \\
\hline
\end{tabular}

\section{Tea}

\begin{tabular}{|c|r|c|}
\hline 1. I always avoid & 2. I sometimes avoid & 3. I do not avoid \\
\hline
\end{tabular}

L-2. If you always or sometimes avoid tea to prevent a relapse, what is the source of this information? (Choose as many as apply)

\begin{tabular}{|l|l|}
\hline 1. & Your own experience \\
\hline 2. & Gastroenterologist / IBD specialist \\
\hline 3. & General practitioner \\
\hline 4. & IBD nurse specialist / other nurse \\
\hline 5. & Dietitian \\
\hline 6. & Internet (patient support organization such as Crohn's and Colitis UK) \\
\hline 7. & Internet (Other websites) \\
\hline 8. & Information leaflet / book for IBD \\
\hline 9. & Other patients with Ulcerative Colitis \\
\hline 10. & Other patients with Crohn's disease \\
\hline 11. & Family \\
\hline 12. & Friends \\
\hline 13. & Social media \\
\hline 14. & Television or Radio \\
\hline 15. & Newspapers and magazines \\
\hline 16. & Other, please specify $\ldots \ldots \ldots \ldots \ldots \ldots \ldots \ldots \ldots \ldots \ldots \ldots \ldots \ldots \ldots \ldots \ldots \ldots \ldots \ldots \ldots \ldots \ldots \ldots \ldots \ldots \ldots \ldots \ldots \ldots \ldots \ldots \ldots \ldots \ldots \ldots \ldots$ \\
\hline
\end{tabular}


M. Other (please specify ...)

\begin{tabular}{|c|r|c|}
\hline 1. I always avoid & 2. I sometimes avoid & 3. I do not avoid \\
\hline
\end{tabular}

M-2. If you always or sometimes avoid other foods or dinks to prevent a relapse, what is the source of this information? (Choose as many as apply)

\begin{tabular}{|l|l|}
\hline 1. & Your own experience \\
\hline 2. & Gastroenterologist / IBD specialist \\
\hline 3. & General practitioner \\
\hline 4. & IBD nurse specialist / other nurse \\
\hline 5. & Dietitian \\
\hline 6. & Internet (patient support organization such as Crohn's and Colitis UK) \\
\hline 7. & Internet (Other websites) \\
\hline 8. & Information leaflet / book for IBD \\
\hline 9. & Other patients with Ulcerative Colitis \\
\hline 10. & Other patients with Crohn's disease \\
\hline 11. & Family \\
\hline 12. & Friends \\
\hline 13. & Social media \\
\hline 14. & Television or Radio \\
\hline 15. & Newspapers and magazines \\
\hline 16. & Other, please specify $\ldots \ldots \ldots \ldots \ldots \ldots \ldots \ldots \ldots \ldots \ldots \ldots \ldots \ldots \ldots \ldots \ldots \ldots \ldots \ldots \ldots \ldots \ldots \ldots \ldots \ldots \ldots \ldots \ldots \ldots \ldots \ldots \ldots \ldots \ldots \ldots \ldots \ldots \ldots$ \\
\hline
\end{tabular}

Q7. Do you consider that consuming certain foods, drink, or nutritional supplements can prevent a relapse of Inflammatory Bowel Disease?

\begin{tabular}{|l|l|} 
1. Yes & 2. No \\
\hline
\end{tabular}

Q8. Do you actually consume certain foods, drink, or nutritional supplements to prevent a relapse of Inflammatory Bowel Disease?

\begin{tabular}{|l|l|} 
1. Yes & 2. No \\
\hline
\end{tabular}

If you answered No please go to Q9

Q8-2. If $\underline{\text { Yes, which foods, drink, or nutritional supplements do you consume? }}$

Foods or drinks such as:

Nutritional supplements such as: 
Q8-3. What are your sources of the information regarding consuming certain foods, drink, or nutritional supplements for relapse prevention?

(Choose as many as apply)

\begin{tabular}{|l|l|}
\hline 1. & Your own experience \\
\hline 2. & Gastroenterologist / IBD specialist \\
\hline 3. & General practitioner \\
\hline 4. & IBD nurse specialist / other nurse \\
\hline 5. & Dietitian \\
\hline 6. & Internet (patient support organization such as Crohn's and Colitis UK) \\
\hline 7. & Internet (Other websites) \\
\hline 8. & Information leaflet / book for IBD \\
\hline 9. & Other patients with Ulcerative Colitis \\
\hline 10. & Other patients with Crohn's disease \\
\hline 11. & Family \\
\hline 12. & Friends \\
\hline 13. & Social media \\
\hline 14. & Television or Radio \\
\hline 15. & Newspapers and magazines \\
\hline 16. & Other, please specify $\ldots \ldots \ldots \ldots \ldots \ldots \ldots \ldots \ldots \ldots \ldots \ldots \ldots \ldots \ldots \ldots \ldots \ldots \ldots \ldots \ldots \ldots \ldots \ldots \ldots \ldots \ldots \ldots \ldots \ldots \ldots \ldots \ldots \ldots \ldots \ldots \ldots \ldots$ \\
\hline
\end{tabular}

Q9. Do you consider the recommended diet in relapse of Inflammatory Bowel Disease to be same as that in remission of Inflammatory Bowel Disease?

\begin{tabular}{l|l} 
1. Yes & 2. No
\end{tabular}

Q10. Do you consider the recommended diet in preventing relapse of Ulcerative Colitis to be same as that in preventing relapse in Crohn's disease?
1. Yes
2. No
3. I don't know

Q11. When you search information for dietary recommendations, are you able to find specific advice for Inflammatory Bowel Disease?
1. Yes
2. No

If your answer is No please move to Q12

Q11-2. If $\underline{\text { Yes}}$, please specify the information resources. 
Q12. Do you avoid the same menu as the other members of the family living with you to prevent a relapse of Inflammatory Bowel Disease?

\begin{tabular}{l|l|l} 
1. I always avoid & 2. I sometimes avoid & 3 . I do not avoid
\end{tabular}

Q13. Do you avoid eating out for fear of causing a relapse of Inflammatory Bowel Disease?
1. I always avoid
2. I sometimes avoid
3. I do not avoid

Q14. Have you heard of or tried any of these specific diets? (please circle)

\begin{tabular}{|c|l|l|}
\hline Gluten free diet & 1. I have heard of this & 2. I have tried this \\
\hline Lactose free diet & 1. I have heard of this & 2. I have tried this \\
\hline Low FODMAPs diet & 1. I have heard of this & 2. I have tried this \\
\hline Specific carbohydrate diet & 1. I have heard of this & 2. I have tried this \\
\hline Anti-inflammatory diet & 1. I have heard of this & 2. I have tried this \\
\hline Paleolithic diet & 1. I have heard of this & 2. I have tried this \\
\hline
\end{tabular}

Finally, some questions about you.

Q15. Are you male or female?

\begin{tabular}{|c|c|}
\hline 1. Male & 2. Female \\
\hline
\end{tabular}

Q16. Please tell us your age?

years old

Q17. How tall are you?

$\mathrm{cm}$

Q18. What is your weight?

Q19. In which country were you born?

If you were born outside of the UK please move to Q20.

Q19.1 If you were born in the UK, were your parents also born in the UK?

1. Yes

2. No 
Q20. With which South Asian ethnicity do you identify yourself (please circle)?

\begin{tabular}{|c|c|}
\hline 1. & Indian \\
\hline 2. & Pakistani \\
\hline 3. & Sri Lankan \\
\hline 4. & Bangladeshi \\
\hline 5. & Nepalese \\
\hline 6. & 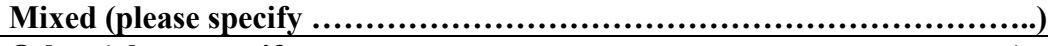 \\
\hline 7. & 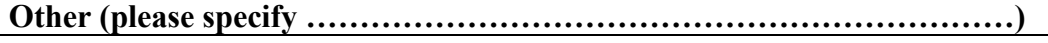 \\
\hline
\end{tabular}

Q21. Do you have any other medical conditions for which you need to avoid certain types of foods or drink? For example diabetes mellitus, high cholesterol, hypertension.

3. Yes

4. No

If Yes please specify

Q22. Who do you live with?

\begin{tabular}{l|l|l} 
1. Family & 2. Alone & 3. Others
\end{tabular}

Q23. Are you working full-time or part-time?

1. Full-time

2. Part-time

3. Unemployed

4. Retired

Q24. What is you highest level of educational qualification?

1. O-levels/GCSEs

2. A-levels

3. University degree

4. Other professional qualifications e.g. diploma

Q25. Do you feel you are limited in your choices with foods or drink because of cost or income?
1. Yes
2. No

Thank you for taking the time to complete this questionnaire. 